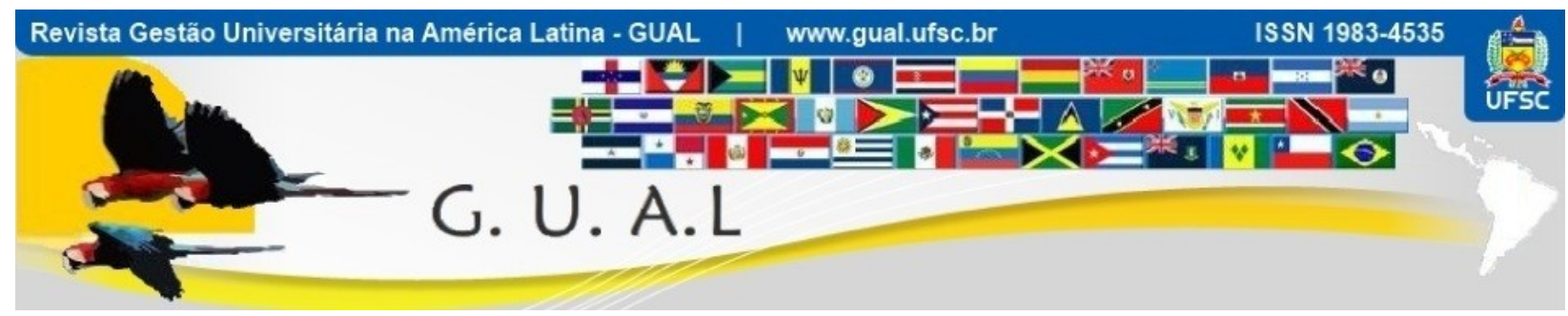

DOI: http://dx.doi.org/10.5007/1983-4535.2013v6n1p287

\title{
CAUSAS DA EVASÃO EM CURSOS DE CAPACITAÇÃO DE TÉCNICOS EM INSTITUIÇÃO DE ENSINO SUPERIOR
}

\section{CAUSES OF DROPOUT IN TECHNICAL TRAINING COURSES IN HIGHER EDUCATION INSTITUTION}

Cecilia Estela Ferreira da Silva Cesar, Graduada Universidade de Brasília - UnB ceciliacesar1@hotmail.com

Maria de Fátima Bruno-Faria, Doutora

Universidade de Brasília - UnB fatimabruno@unb.br

Recebido em 22/novembro/2012

Aprovado em 28/dezembro/2012

Sistema de Avaliação: Double Blind Review

Esta obra está sob uma Licença Creative Commons Atribuição-Uso. 


\title{
CAUSAS DA EVASÃO EM CURSOS DE CAPACITAÇÃO DE TÉCNICOS EM INSTITUIÇÃO DE ENSINO SUPERIOR \\ DOI: http://dx.doi.org/10.5007/1983-4535.2013v6n1p287
}

\section{RESUMO}

Este estudo teve como objetivo identificar as causas da evasão em cursos ofertados aos servidores técnicos administrativos em uma Instituição Federal de Ensino Superior localizada no Distrito Federal. Dentre os diferentes conceitos de evasão adotou-se a concepção de Silva Filho (2007), que considera como a situação em que o aluno não conclui um curso no qual se matriculou, em qualquer uma de suas fases (início, meio ou próximo ao final). Foi adotada como metodologia a pesquisa qualitativa com o uso das técnicas de análise de documento e entrevistas semiestruturadas. A pesquisa qualitativa procurou identificar as causas da evasão, seus índices por período e estratégias para a sua redução. Os resultados revelaram que os maiores índices de evasão se apresentam no começo do curso. Esses foram motivados por fatores organizacionais como, falta de apoio da chefia, excesso de trabalho, falta de informações sobre as regras de oferta dos cursos e horário das aulas. Constatou-se também que as causas da evasão assemelham-se as encontradas em vários estudos realizados, apesar do foco destas pesquisas serem a evasão em cursos presenciais de nível superior e não cursos de capacitação, embora alguns aspectos típicos da realidade da IFES tenham sido evidenciados neste estudo. Também foram apresentadas sugestões de estratégias que visassem à redução da evasão.

Palavras-chave: Evasão. Capacitação. Retenção.

\begin{abstract}
This study aimed to identify the causes of dropout in courses offered at servers administrative staff in a Federal Institution of Higher Education in the Federal District. Among the different concepts of dropout adopted the design of Silva Filho (2007), which considers the situation in which the student does not complete a course in which enrolled in any of its phases (beginning, middle or near the end). It was adopted as a qualitative research methodology with the use of document analysis techniques and semi-structured interviews. Qualitative research sought to identify the causes of the dropout, their indices by period and strategies for their reduction. The results revealed that the highest dropout rates are presented at the beginning of the course. These were motivated by organizational factors such as, lack of support from management, overwork, lack of information about the rules for supply of courses and class schedule. It was also found that the causes of dropout are similar to those found in several studies, although the focus of this research is the dropout of classroom courses in higher education and not training courses, although some aspects of reality typical of IFES has been evidenced in this study. Also presented were suggestions of strategies that aimed at reducing dropout.
\end{abstract}

Keywords: Dropout. Training. Retention 


\section{CAUSAS DA EVASÃO EM CURSOS DE CAPACITAÇÃO DE TÉCNICOS EM INSTITUIÇÃO DE ENSINO SUPERIOR \\ DOI: http://dx.doi.org/10.5007/1983-4535.2013v6n1p287}

\section{INTRODUÇÃO}

Um dos objetivos do treinamento é preparar para novas funções, introduzindo novas tecnologias no trabalho. Sendo assim, Menegasso et al. (2001) entendem que a melhoria da qualidade da prestação dos serviços públicos passa pela revisão dos processos de trabalho, informatização das suas rotinas e, pela capacitação dos servidores. O treinamento, que antigamente visava apenas a mecanização e a grande produção em massa, atualmente busca o desenvolvimento que tenha reflexo nas ações organizacionais.

Observa-se uma mudança na percepção da gestão pública, especialmente nas universidades. Em algumas Universidades Federais foram criadas Pró-Reitorias de Gestão de Pessoas que promovem ações direcionadas ao treinamento e desenvolvimento dos servidores. O foco do presente estudo recai na Coordenadoria de Capacitação (PROCAP) do Decanato de Gestão de Pessoas (DGP) da Universidade de Brasília (UnB). Essa tem por função a atualização dos Recursos Humanos da Universidade, com o objetivo do aumento da qualidade dos seus serviços, da qualidade de vida e da qualificação profissional. Para este fim busca adequar o perfil de servidores e colaboradores por meio de um processo contínuo de treinamento.

Após a análise de documentos expedidos pela Coordenação de Capacitação e Educação (PROCAP), constatou-se em 2011 um índice de evasão de técnicos administrativos superior a $26 \%$ em seus cursos de capacitação. Constatou-se ainda que não existia um estudo sistemático das causas da evasão dos cursos oferecidos pela PROCAP. Este fato corrobora os estudos de Silva Filho (2007) que diz que "a evasão é um problema que afeta o resultado dos sistemas educacionais. As perdas de estudantes que iniciam e não concluem seus cursos são desperdícios sociais, acadêmicos e econômicos". Afirma que poucas Instituições Federais de Ensino Superior (IFES) têm ações com o intuito de acompanhar e prevenir a evasão.

Por consequência, este artigo busca identificar as causas da evasão em diferentes cursos oferecidos aos servidores técnicos administrativos da Instituição, que trará subsídios à definição de estratégias destinadas à sua redução.

Para o alcance desse objetivo, este artigo encontra-se estruturado em cinco seções além desta breve introdução; tem-se a fundamentação teórica; metodologia; resultados e discussão e conclusões. 


\section{CAUSAS DA EVASÃO EM CURSOS DE CAPACITAÇÃO DE TÉCNICOS EM INSTITUIÇÃO DE ENSINO SUPERIOR \\ DOI: http://dx.doi.org/10.5007/1983-4535.2013v6n1p287}

\section{FUNDAMENTAÇÃO TEÓRICA}

\subsection{CAPACITAÇÃO NO SETOR PÚBLICO}

De acordo com Gaetani et al. (2007) a capacitação de recursos humanos é condição essencial para a formulação de novos arranjos institucionais para que se possa reabilitar o Estado. Considera-se o treinamento e a capacitação funcional como processos permanentes e contínuos, que podem se tornar ferramentas eficazes, dinâmicas e rápidas, como processos educativos por excelência, enquanto facilitadores da aprendizagem, do crescimento e do desenvolvimento psicossocial e intelectual dos servidores.

A capacitação no setor público encontra-se associada à noção de competências. A gestão por competências da área de gestão de pessoas, é tratada formalmente pelo governo federal no Decreto 5.707 (BRASIL, 2006), que institui a Política Nacional de Desenvolvimento de Pessoal (PNDP), a ser implementada pelos órgãos e entidades da Administração Pública. No artigo $2^{\circ}$, inciso II, é definida como "a gestão da capacitação orientada para o desenvolvimento do conjunto de habilidades e atitudes necessárias ao desempenho das funções dos servidores, visando ao alcance dos objetivos da instituição."

No Decreto $n^{0} 5.825$ (BRASIL, 2006) são estabelecidas as diretrizes para a elaboração do Plano de Desenvolvimento dos Integrantes do Plano de Carreira dos Cargos TécnicoAdministrativos da Educação, onde prevê em seu artigo $2^{\circ}$ inciso III, a adequação do quadro de pessoal às demandas institucionais e no artigo $7^{\circ}$ o Programa de Capacitação e Aperfeiçoamento com seus objetivos.

Após a implantação de um curso se faz necessário averiguar se seus objetivos foram atendidos e, se for o caso, analisar as causas do não atendimento. Para este fim, a seguir apresentam-se as características da avaliação de treinamentos e de alguns modelos teóricos destinados a sua compreensão.

\subsection{TREINAMENTO, DESENVOLVIMENTO E EDUCAÇÃO}

A expressão "Treinamento, Desenvolvimento e Educação" (TD\&E) surgiu da expressão “desenvolvimento de recursos humanos", segundo Borges Andrade (2006, p.142).

Para Borges Andrade et al (2006, p. 160) “o treinamento é uma ação tecnológica, controlada pela organização, formada por partes inseridas no sistema organizacional com a finalidade de promover a melhoria do desempenho, capacitar para o uso de novas tecnologias e preparar para novas funções". Para Borges Andrade et al. (2006, p. 145) "o 


\section{CAUSAS DA EVASÃO EM CURSOS DE CAPACITAÇÃO DE TÉCNICOS EM INSTITUIÇÃO DE ENSINO SUPERIOR \\ DOI: http://dx.doi.org/10.5007/1983-4535.2013v6n1p287}

desenvolvimento, consiste no conjunto de experiências e oportunidades proporcionadas pela organização com o intuito de incentivar o crescimento profissional e pessoal do seu empregado". A educação é constituída de um conjunto de programas educacionais ministrados a médio e longo prazo, que objetivam qualificar continuamente os empregados. Os cursos analisados neste artigo são considerados treinamentos, pois são ações educacionais de curta ou média duração que visam à capacitação dos servidores da Universidade de Brasília.

Os programas de formação e qualificação profissional têm a função de contribuir para que os indivíduos adquiram novas competências continuamente, as quais serão exigidas pelo mercado no qual pretendem inserir-se ou permanecer. Segundo Zerbini (2007), a qualificação profissional apresenta-se como um conjunto de habilidades, conhecimentos e competências, das quais o indivíduo dispõe para seu desempenho profissional.

Segundo Borges Andrade (2002, p. 32) "devido às rápidas mudanças, T \& D têm crescido de importância pois através deles, são adquiridas habilidades, o desenvolvimento de estratégias cognitivas e atitudes, que poderão tornar o indivíduo mais competente para desempenhar seu papel em diversas organizações". Segundo Abbad (1999) há um crescente interesse de pesquisadores nacionais e estrangeiros pelo tema avaliação de treinamento, procurando a consolidação de modelos teórico-metodológicos eficazes como os de Hamblin (1978), Borges Andrade (2006) e Abbad (1999).

Para Borges-Andrade (2006) a avaliação de treinamento caracteriza-se como um conjunto de atividades e métodos a serem utilizados na validação das informações sobre a efetividade de um dado. A avaliação tem um papel relevante, pois fornece informações sobre as ações de treinamento realizadas que subsidiam a prática organizacional. Afirma também que um dos principais objetivos de uma avaliação de treinamento é fazê-lo funcionar e tornálo válido. A implementação de um treinamento em uma organização ocorre por diversos motivos, como o aprendizado de novas ferramentas, a melhora de uma competência ou a mudança de comportamentos. Para que se possa medir efetivamente o treinamento realizado e saber se gerou benefícios organizacionais, são utilizados modelos de avaliação de treinamento.

Nos estudos realizados sobre avaliação de treinamentos presenciais, sabe-se que grande parte dos investimentos tende a ser desperdiçada devido a problemas relativos ao planejamento instrucional. Esses sistemas auxiliam no planejamento de futuras atividades 


\section{CAUSAS DA EVASÃO EM CURSOS DE CAPACITAÇÃO DE TÉCNICOS EM INSTITUIÇÃO DE ENSINO SUPERIOR \\ DOI: http://dx.doi.org/10.5007/1983-4535.2013v6n1p287}

instrucionais podendo ser utilizados para a redução das causas da evasão, tema a ser tratado a seguir.

\subsection{EVASÃO: CONCEITOS, TIPOS E ASPECTOS}

São diversos os conceitos e tipos de evasão identificados na literatura revisada. O Instituto Nacional de Pesquisas sobre Educação Anísio Teixeira (INEP) considera abandono, a saída do aluno da escola ou curso por um período de tempo com posterior retorno. Já na evasão o aluno sai da escola ou curso e não retorna mais.

Na literatura nacional o termo mais utilizado é evasão. Já na literatura internacional (TINTO, 1973; BEAN, 1980, 1983) e outros, para tratar do tema evasão são persistência ou não persistência para explicar se o aluno chega à conclusão do curso.

Para Peralta (2008) a evasão pode ser definida como uma saída voluntária, que pode ser explicada por diferentes categorias de variáveis: socioeconômica, individual, institucional e acadêmica. No entanto, a forma de entender as mesmas depende do nível de análise; isto é, individual, institucional e estadual ou nacional. Já para Tinto (1973) a evasão é uma situação que o aluno enfrenta quando procura, mas não consegue concluir o seu projeto educativo.

De acordo com Silva Filho (2007) há mais de um tipo de evasão: a evasão total mede o número de alunos que, tendo entrado num determinado curso, IES ou sistema de ensino, não obteve o diploma ao final do curso. O outro tipo de evasão é chamado de evasão anual média, que mede a percentagem de alunos evadidos de um sistema de ensino, em um determinado período de tempo, que pode ser semestral ou anual.

Para a realização deste estudo, devido à opção teórica, considerou-se o termo evasão como a saída definitiva do inscrito do curso, onde não há a possibilidade de retorno àquela turma específica.

Veloso (2001) afirma que nos últimos anos, esse tema tem sido objeto de alguns estudos e análises, especialmente em países do primeiro mundo e têm demonstrado que o tema é universal e como possui características de comportamento semelhantes apesar das diferenças entre as instituições de ensino e das peculiaridades socioeconômicas de cada país.

Um estudo realizado por Bordas (1996) aponta que, apesar do tema ser relevante para as instituições de ensino, muitas ainda não perceberam a importância da análise da evasão e desperdiçam grande parte de recursos orçamentários por não saberem como administrá-la. 


\section{CAUSAS DA EVASÃO EM CURSOS DE CAPACITAÇÃO DE TÉCNICOS EM INSTITUIÇÃO DE ENSINO SUPERIOR \\ DOI: http://dx.doi.org/10.5007/1983-4535.2013v6n1p287}

\subsection{EVASÃO: CAUSAS}

A pesquisa sobre as possíveis causas da evasão ou persistência do estudante nos cursos encontrou apoio nos estudos feitos por Spady (1970), Tinto (1973), Bean (1980, 1983), Paredes (1994), Biazus (2003), Gaioso (2005) e Silva Filho (2007) e outros.

Spady (1970) baseou seus estudos nas teorias de Durkhein sobre suicídio. Essa teoria explica que o suicídio é comum quando o indivíduo não está integrado à produção da sociedade. Em decorrência deste fato a probabilidade do suicídio cresce, devido a ausência de afiliação coletiva e de integração moral. Com base nesta premissa, Spady (1970) propôs um modelo que acredita que o indivíduo que compartilha valores com o grupo social tem menos tendência a abandonar o curso, do que aqueles que não compartilham. Embora estudos tenham sido desenvolvidos para explicar as decisões do aluno ao longo do curso, o Modelo de Integração de Tinto (1973) baseado em Spady e o Modelo de Atrito de Bean (1980, 1983) destacaram-se, ao fornecer uma estrutura de compreensão dos fatores que influenciam as decisões dos alunos.

A seguir o modelo de Tinto (1973) para a evasão ou persistência, representado na Figura 1:

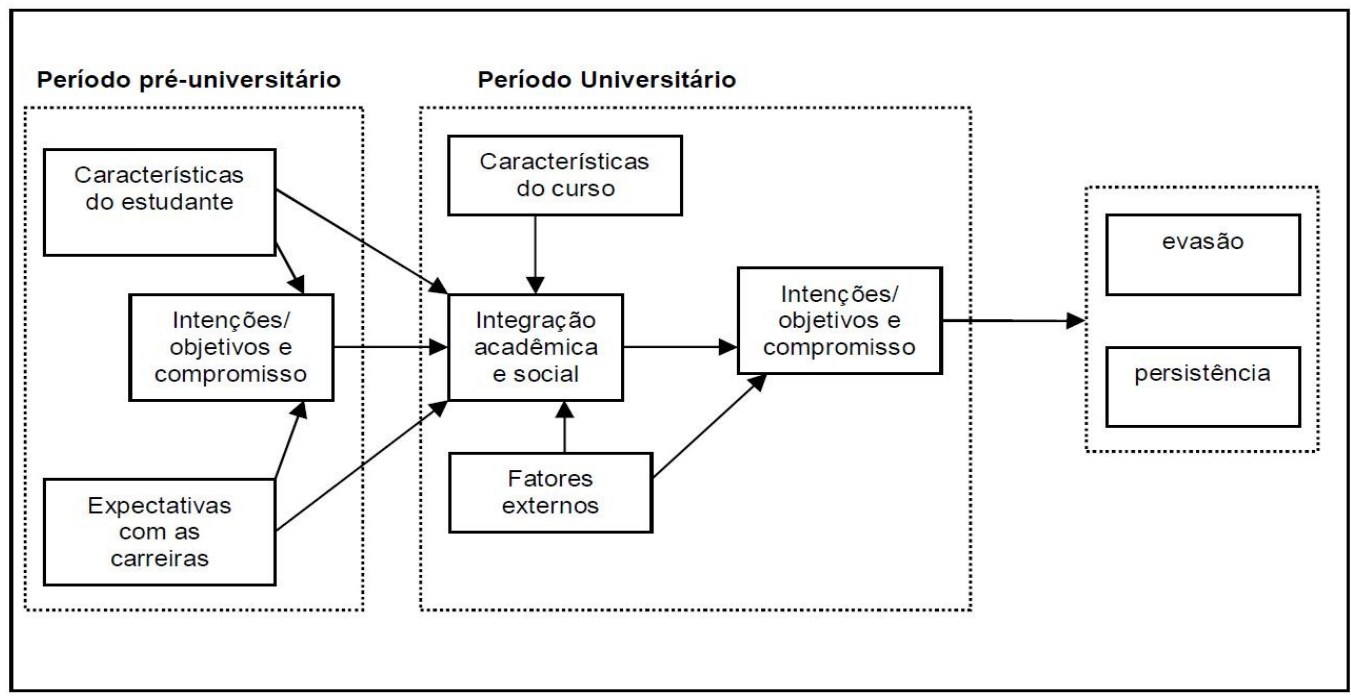

Figura 1 Modelo de Vincent Tinto (1973, p. 42)

Fonte: Adaptado por Costa (2010, p.47)

Tinto continou os estudos de Spady e em 1973 propôs o seu modelo teórico (Figura 1) sobre a evasão. Neste modelo o autor interpreta que, a integração, a adaptação social e acadêmica do estudante na instituição determinará a sua decisão de permanecer ou não no 


\section{CAUSAS DA EVASÃO EM CURSOS DE CAPACITAÇÃO DE TÉCNICOS EM INSTITUIÇÃO DE ENSINO SUPERIOR \\ DOI: http://dx.doi.org/10.5007/1983-4535.2013v6n1p287}

curso. Este modelo centra-se em dois aspectos: no indivíduo, sua bagagem pessoal e cultural e na Instituição, no que ela pode oferecer em aspectos culturais e de integração.

A seguir o modelo de Bean (1980) representado na Figura 2:

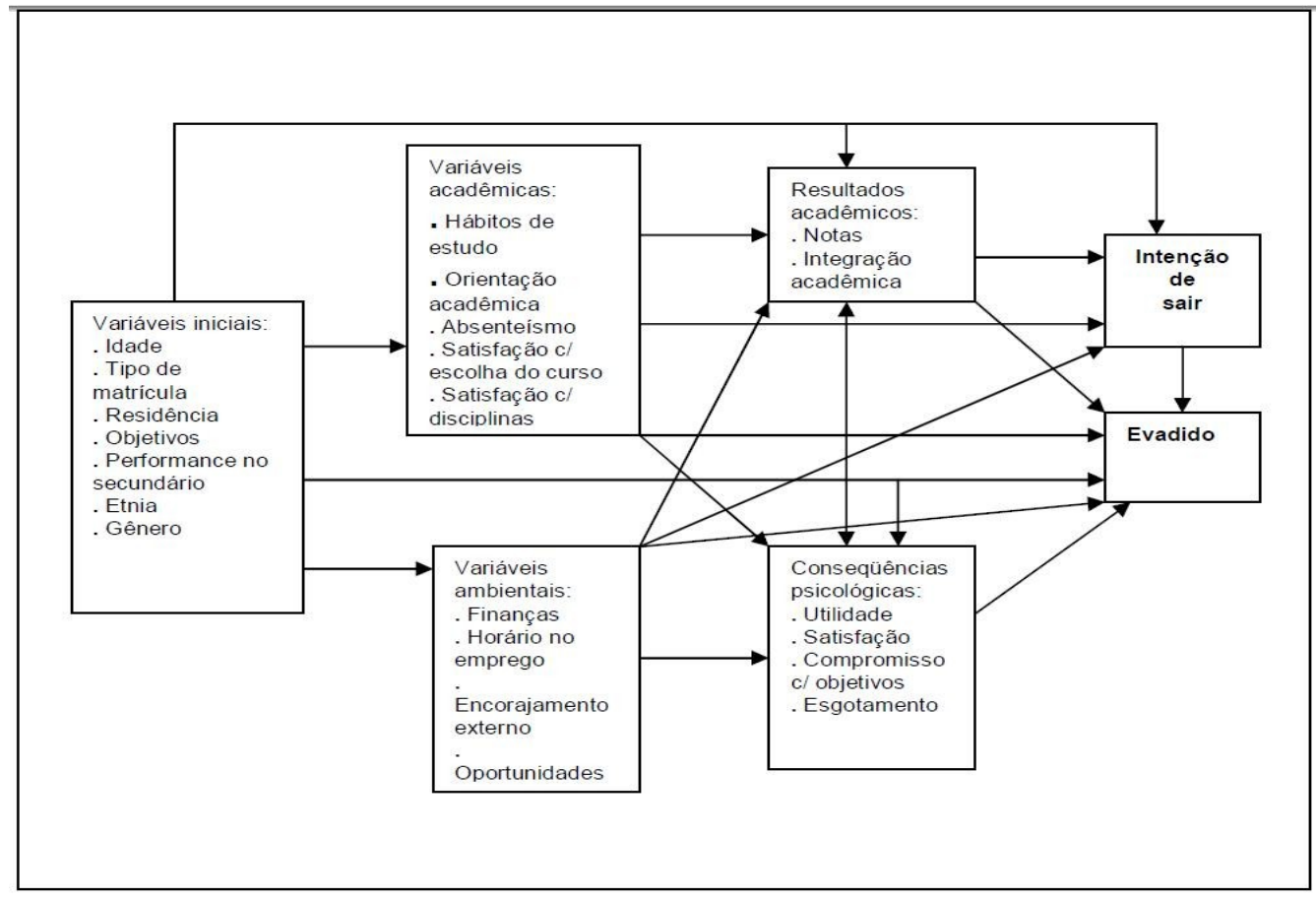

Figura 2 Modelo de Bean (1980)

Fonte: Adaptado por Costa (2010, p.49)

Segundo Bean $(1980,1983)$, como consta na Figura 2, a decisão do aluno de evadir-se ou não, relaciona-se com a sua adaptação, bem como fatores externos, aprovação da família, encorajamento dos amigos e situação financeira, considerada nos casos de cursos de nível superior em instituições privadas como fator determinante de evasão. O modelo proposto pelo autor indica que a decisão de evasão ou de permanência em um curso é um processo, em que opiniões podem influenciar as atitudes.

O ponto divergente entre os modelos teóricos citados anteriormente é que para Tinto (1973) a causa da evasão está centrada na relação da Instituição com o indivíduo, e para Bean (1980) a influência de fatores externos também pode motivar a decisão de evadir ou não.

No que diz respeito às pesquisas empíricas, o tema evasão tem um grande número de publicações em periódicos científicos nacionais e internacionais.

Veloso (2001) fez um estudo sobre a evasão nos cursos de graduação da Universidade Federal de Mato Grosso. Seu objetivo era o de explicar os índices de evasão dos cursos de graduação da Universidade Federal de Mato Grosso sob a ótica institucional. Para este fim 


\section{CAUSAS DA EVASÃO EM CURSOS DE CAPACITAÇÃO DE TÉCNICOS EM INSTITUIÇÃO DE ENSINO SUPERIOR \\ DOI: http://dx.doi.org/10.5007/1983-4535.2013v6n1p287}

aplicou questionários, realizou entrevistas e realizou análise de dados. Os dados obtidos informaram que a evasão nos cursos de graduação da Universidade Federal de Mato Grosso, campus de Cuiabá, de acordo com Veloso (2001) é um fenômeno institucional, reflexo da ausência de uma política de permanência do aluno no curso de sua opção. Observou também que essa evasão caracteriza-se como um fator de exclusão do processo educacional, dentre tantos outros impostos aos alunos.

Outro aspecto importante apurado por Veloso (2001) é que a Instituição deve desenvolver ações tais como a comunicação de seus cursos através da produção de materiais de divulgação junto aos estudantes do ensino médio; o desenvolvimento de programas de intercâmbio junto às escolas, principalmente as públicas, visando oferecer esclarecimento quanto à opção profissional de seus alunos; e também, após o ingresso, o desenvolvimento de ações de acompanhamento e integração do aluno à vida universitária.

Biazus (2003) realizou uma pesquisa sobre os alunos evadidos do Curso de Ciências Contábeis da UFSM e UFSC no período de Janeiro de 1993 a dezembro de 2002. Seu objetivo era de elaborar uma proposta de melhoria contínua no processo da qualidade do ensino dos Cursos de Ciências Contábeis da UFSM/UFSC. Para esse fim, utilizou-se de um instrumento de coleta de dados primário (questionário). Seus resultados apresentaram dados quanto a gênero, faixa etária e período em que ocorreu a evasão, bem como características no que se refere à carga horária de trabalho exercida por mais de $50 \%$ dos evadidos que era superior a 30 horas. Informou também que os evadidos não ingressaram em outros cursos e que teriam interesse em retornar ao curso.

Gaioso (2005) realizou um estudo sobre a evasão em uma IES no período de 2000 a 2003. Seu objetivo era de estudar a evasão e suas diversas causas sob o ponto de vista do aluno. Para atingir estes objetivos realizou entrevistas e posterior análise qualitativa. Suas conclusões foram de que a evasão dos cursos nas instituições públicas se dá pela incompatibilidade entre horário de estudo e trabalho, falta de orientação profissional, desconhecimento da metodologia do curso, deficiência da educação básica, busca de herança profissional, mudança de endereço, problemas financeiros, concorrência entre as IES privadas, imaturidade, reprovação sucessiva, falta de perspectivas de trabalho, ausência de laços afetivos na universidade, falta de um referencial na família, entrada na faculdade por imposição, casamentos não planejados e nascimento de filhos. 


\section{CAUSAS DA EVASÃO EM CURSOS DE CAPACITAÇÃO DE TÉCNICOS EM INSTITUIÇÃO DE ENSINO SUPERIOR \\ DOI: http://dx.doi.org/10.5007/1983-4535.2013v6n1p287}

Castaño (2006) procurou identificar os principais fatores associados à evasão na Universidade de Antioquia em Medellin na Colombia através da análise dos determinantes da evasão. Para isto, utilizou a aplicação de modelos de regressão de risco proporcional Prentice e Gloeckler (1978) e Meyer (1990). O estudo mostrou que os fatores individuais, acadêmicos, sócio- econômicos e institucionais são determinantes na evasão da graduação e que as variáveis presentes em cada um deles explicam as diferenças de decisões entre os estudantes.

Cardoso (2008) desenvolveu um estudo sobre a análise dos efeitos das políticas de cotas na Universidade de Brasília (UnB), sob o ponto de vista do rendimento e evasão dos alunos cotistas. O estudo investigou o impacto do programa de cotas sob o rendimento e a evasão dos alunos cotistas para atingir este objetivo utilizou-se da análise qualitativa. Verificou que os cotistas evadem em proporções menores que os não cotistas e, além disso, os cotistas que trabalhavam estavam indecisos sobre a escolha do curso e que, no momento da inscrição, evadiram em maior proporção que os cotistas que não trabalhavam ou que estavam absolutamente decididos quanto à escolha do curso.

Nos estudos relatados anteriormente, as causas da evasão encontradas foram: aspectos financeiros relacionados à vida pessoal ou familiar do estudante; aspectos relacionados à escolha do curso, expectativas no ingresso, nível de satisfação com o curso e com a universidade; dificuldades de relacionamento com colegas e docentes; aprovação, reprovação e repetência; baixo prestígio social do curso, da profíssão e da universidade; incompatibilidade entre os horários de estudos com as demais atividades, como, por exemplo, o trabalho; aspectos familiares como, por exemplo, responsabilidades com filhos e dependentes, apoio familiar quanto aos estudos e baixo nível de motivação ou compromisso com o curso, indicando o aluno como o responsável pela decisão de evadir ou permanecer no ensino superior.

Tinto (1973) afirma que nenhuma definição pode abranger a total complexidade deste fenômeno, e que cabe aos pesquisadores a escolha da definição que melhor se adequa aos seus objetivos e problema de pesquisa.

Este estudo teve foco nas causas de evasão dos cursos de capacitação presenciais oferecidos pela PROCAP. Para sua realização, buscou-se identificar quaisquer tipos de causas de evasão institucional. 


\section{CAUSAS DA EVASÃO EM CURSOS DE CAPACITAÇÃO DE TÉCNICOS EM INSTITUIÇÃO DE ENSINO SUPERIOR \\ DOI: http://dx.doi.org/10.5007/1983-4535.2013v6n1p287}

\section{METODOLOGIA}

Para Lüdke (1986) a análise documental é uma fonte natural de informação que pode apontar problemas a serem explorados através de outros métodos de pesquisa. Nesta pesquisa foi realizada a análise quantitativa e qualitativa de documentos que pudessem contribuir para a compreensão das causas da evasão.

Segundo Flick (2009) a utilização da entrevista semipadronizada justifica-se pelo fato de que os entrevistados possuem uma reserva de conhecimentos sobre o tópico em estudo. $\mathrm{Na}$ análise documental foram analisados todos os documentos (cópias das folhas de frequência dos cursos (4), lista de alunos evadidos (1), lista dos instrutores (1) e catálogo de cursos de capacitação para os servidores) fornecidos pela instituição pesquisada. O Catálogo de Cursos foi elaborado pela PROCAP e contém informações sobre todos os cursos ofertados, carga horária, público alvo, modalidade e período de realização.

Os cursos avaliados foram oferecidos pelo Decanato de Gestão de Pessoas, através da PROCAP, ao público interno da Fundação Universidade de Brasília (FUB) e foram avaliados um total de quatro cursos presenciais: Formação Gerencial, Francês Básico, Inglês Instrumental e Iniciação ao Serviço Público.

Inicialmente, objetivou-se adotar o critério de exaustão na composição da amostra (ZANELLI, 2002), incluindo toda a população de evadidos constituída pelos 57 servidores evadidos dos cursos, dada a dificuldade de acesso aos mesmos foi possível entrevistar 25 servidores evadidos. Foram entrevistados também não evadidos, técnicos, instrutores e o Diretor da área. Como instrumentos de coleta de dados foram utilizados roteiros de entrevista semi estruturados para os entrevistados e um pequeno questionário com itens sobre dados demográficos a ser respondido logo após o término de cada entrevista.

Foram elaborados cinco roteiros, um para cada grupo de entrevistados: evadidos, não evadidos, instrutor, técnicos e gestor. Os roteiros tinham perguntas adequadas a cada grupo de entrevistados abordando o tema evasão, satisfação com o curso e possíveis sugestões para a redução da evasão. Após a realização das entrevistas, as mesmas foram transcritas para posterior análise com emprego da técnica de análise de conteúdo, a fim de criar categorias que evidenciassem as causas da evasão na perspectiva dos diferentes entrevistados. Para Bardin (2011, p. 147) "a categorização é uma operação de classificação de elementos constitutivos de um conjunto por diferenciação e, em seguida, por reagrupamento segundo o gênero (analogia) e com critérios previamente definidos." Os resultados foram organizados de modo a conter o 
nome da categoria, a definição operacional (PASQUALI, 1998) e exemplo ilustrativo de fala de entrevistados, separando por tipo de entrevistado. Foi realizada triangulação de pesquisadores que, de acordo com Guion (2002) consiste na utilização da perspectiva de vários profissionais ou colegas da área na interpretação de um conjunto de informações.

\section{RESULTADOS E DISCUSSÃO}

\subsection{PESQUISA DOCUMENTAL}

Em relação aos quatro cursos pesquisados, os índices de evasão no período de abril a setembro de 2011 foram: Formação Gerencial (37,7\%), Inglês Instrumental (35\%), Francês Básico (33,3\%) e Iniciação ao Serviço Público (26,19\%).

Quanto ao Catálogo de Cursos de Capacitação sua análise proporcionou informações que permitiram conhecer como são ofertados os cursos e a legislação que pauta esta oferta. Ele contém as informações quanto aos objetivos, número de vagas, horário de realização, público alvo, pré-requisitos e modalidade de cada curso ofertado no ano.

Tabela 1 Cursos Analisados

\begin{tabular}{|c|c|c|c|c|}
\hline Nome do Curso & Objetivo & Público Alvo & Vagas & $\begin{array}{l}\text { Carga } \\
\text { Horária }\end{array}$ \\
\hline $\begin{array}{l}\text { Formação } \\
\text { Gerencial }\end{array}$ & $\begin{array}{l}\text { Espera-se que, ao final deste Programa, } \\
\text { os servidores que desenvolvem ou } \\
\text { pretendem desenvolver atividades de } \\
\text { gestão possam identificar aspectos } \\
\text { essenciais à gestão e explicar como } \\
\text { podem ser aplicados tais conteúdos no } \\
\text { ambiente de trabalho no Serviço Público } \\
\text { Federal, especialmente na UnB. }\end{array}$ & $\begin{array}{c}\text { Servidores } \\
\text { técnico- } \\
\text { administrativos } \\
\text { e servidores } \\
\text { docentes }\end{array}$ & 50 & $180 \mathrm{~h}$ \\
\hline Francês Básico & $\begin{array}{l}\text { Ao final do Curso o servidor-aluno estará } \\
\text { apto a reconhecer as estruturas básicas da } \\
\text { Língua Francesa, mostrando } \\
\text { desenvoltura nas habilidades de } \\
\text { expressão oral e escrita; demonstrando } \\
\text { compreensão auditiva e de leitura no } \\
\text { nível básico; e demonstrando que está } \\
\text { familiarizado com os aspectos } \\
\text { socioculturais que fazem parte da } \\
\text { competência comunicativa em diversos } \\
\text { contextos de âmbito geral. }\end{array}$ & $\begin{array}{c}\text { Servidores } \\
\text { técnico- } \\
\text { administrativos } \\
\text { e servidores } \\
\text { docentes }\end{array}$ & 25 & $45 \mathrm{~h}$ \\
\hline $\begin{array}{c}\text { Inglês } \\
\text { Instrumental }\end{array}$ & $\begin{array}{l}\text { Ao final do semestre o servidor-aluno } \\
\text { deverá demonstrar habilidade de leitura } \\
\text { e interpretação de textos técnicos e } \\
\text { acadêmicos em Língua Inglesa; e } \\
\text { reconhecer as estruturas básicas da } \\
\text { língua inglesa e suas funções no interior } \\
\text { de um texto, aumentando o seu } \\
\text { vocabulário. }\end{array}$ & $\begin{array}{c}\text { Servidores } \\
\text { técnico- } \\
\text { administrativos } \\
\text { e servidores } \\
\text { docentes }\end{array}$ & 20 & $45 \mathrm{~h}$ \\
\hline $\begin{array}{c}\text { Iniciação ao } \\
\text { Serviço Público }\end{array}$ & $\begin{array}{l}\text { Ao final deste programa os servidores } \\
\text { deverão ser capazes de identificar as }\end{array}$ & $\begin{array}{l}\text { Servidores } \\
\text { técnico- }\end{array}$ & $\begin{array}{c}\text { Todos } \\
\text { os }\end{array}$ & $62 \mathrm{~h}$ \\
\hline
\end{tabular}




\section{CAUSAS DA EVASÃO EM CURSOS DE CAPACITAÇÃO DE TÉCNICOS EM INSTITUIÇÃO DE ENSINO SUPERIOR}

DOI: http://dx.doi.org/10.5007/1983-4535.2013v6n1p287

\begin{tabular}{l|l|c|c|c}
\hline & $\begin{array}{l}\text { funções do Estado e as especificidades } \\
\text { do serviço público; descrever a }\end{array}$ & $\begin{array}{c}\text { administrativos } \\
\text { e servidores } \\
\text { instituição UnB, sua missão e a conduta }\end{array}$ & $\begin{array}{c}\text { servido } \\
\text { res } \\
\text { recém } \\
\text { esperada do servidor na Universidade } \\
\text { para integrar-se nesse ambiente } \\
\text { institucional. }\end{array}$ & $\begin{array}{c}\text { ados } \\
\text { ados }\end{array}$ \\
\hline
\end{tabular}

Fonte: Dados da Pesquisa - Elaborado pela Autora

A tabela 1 mostra que dos quatro cursos ofertados três eram de curta duração e um de longa duração, dividido em módulos. Cabe destacar que o próprio servidor é que decide sobre sua inscrição no curso e ele mesmo toma a iniciativa de realizar os procedimentos para a sua participação.

\subsection{RESULTADO DAS ENTREVISTAS}

Os resultados obtidos permitiram a definição das categorias constantes do Quadro 1 como causas da evasão. Com o intuito de facilitar a compreensão, esse Quadro apresenta um resumo das categorias distribuídas entre os grupos participantes da pesquisa.

\begin{tabular}{|c|c|c|c|c|c|}
\hline Categorias & Evadidos & $\begin{array}{c}\text { Não } \\
\text { Evadidos }\end{array}$ & Técnicos & Instrutores & Gestor \\
\hline $\begin{array}{lrrr}\text { Dificuldade de } & \text { acesso } & \text { a } \\
\text { informações junto à PROCAP } & \end{array}$ & $\checkmark$ & & & & \\
\hline Incompatibilidade de horário & $\checkmark$ & & $\checkmark$ & & \\
\hline $\begin{array}{l}\text { Dificuldade de conciliar atividades } \\
\text { diversas }\end{array}$ & $\checkmark$ & $\checkmark$ & & & \\
\hline $\begin{array}{l}\text { Falta de interesse em fazer/concluir } \\
\text { o curso }\end{array}$ & $\checkmark$ & & & & \\
\hline Falta de apoio da chefia & $\checkmark$ & $\checkmark$ & $\checkmark$ & $\checkmark$ & $\checkmark$ \\
\hline Excesso de trabalho & $\checkmark$ & & & & \\
\hline Horário das aulas & $\checkmark$ & & & & \\
\hline $\begin{array}{l}\begin{array}{l}\text { Inadequação da composição da } \\
\text { turma }\end{array} \\
\end{array}$ & $\checkmark$ & & & & \\
\hline $\begin{array}{lll}\text { Inadequação do curso às } \\
\text { necessidades do aluno }\end{array}$ & & $\checkmark$ & & & \\
\hline Duração dos cursos & $\checkmark$ & & $\checkmark$ & & \\
\hline $\begin{array}{l}\text { Dificuldade de conciliar atividades } \\
\text { diversas }\end{array}$ & & & & & \\
\hline $\begin{array}{l}\text { Realização de curso que não conta } \\
\text { para a progressão }\end{array}$ & & $\checkmark$ & & & \\
\hline $\begin{array}{l}\text { Dificuldade de aplicação das regras } \\
\text { de oferta dos cursos }\end{array}$ & & $\checkmark$ & $\checkmark$ & & $\checkmark$ \\
\hline $\begin{array}{l}\text { Adequação do calendário dos } \\
\text { cursos ao ano letivo }\end{array}$ & & & & $\checkmark$ & \\
\hline $\begin{array}{lclr}\text { Necessidade } & \text { de } & \text { priorizar } & \text { a } \\
\text { capacitação } & \text { no } & \text { âmbito } & \text { da } \\
\text { Instituição } & & & \\
\end{array}$ & & & & & $\checkmark$ \\
\hline $\begin{array}{l}\text { Falta de sistemas de apoio à } \\
\text { capacitação }\end{array}$ & & & & & $\checkmark$ \\
\hline
\end{tabular}

Quadro 1 Categorias de causas da evasão segundo os grupos entrevistados 


\section{CAUSAS DA EVASÃO EM CURSOS DE CAPACITAÇÃO DE TÉCNICOS EM INSTITUIÇÃO DE ENSINO SUPERIOR}

DOI: http://dx.doi.org/10.5007/1983-4535.2013v6n1p287

$\mathrm{Na}$ análise das entrevistas dos evadidos foram identificadas nove categorias de motivadores da evasão. A categoria que apresentou maior frequência na fala deste grupo trata da dificuldade de acesso a informações junto à PROCAP. Dada a extensão do artigo, para ilustrar as categorias foram escolhidos apenas dois exemplos de falas.

A Categoria 1, a Dificuldade de acesso a informações junto a PROCAP, foi definida como problemas de comunicação entre a PROCAP e o servidor relativos à confirmação de inscrição ou de continuação de módulos, cujo exemplo de verbalização de dois dos entrevistados é relatado a seguir:

E10: "Eu fiz dois módulos, e os outros dois, não... não tive, assim, retorno da... da PROCAP ou um... Porque o contato era feito por e-mail, né?! Eu não fiquei sabendo se terminou o curso. Não tive mais contato, né?! Os outros dois módulos "ficou" dependendo de... de investir em instrutor para dar o módulo, né?! Os outros dois módulos. E aí, eu cheguei a ligar umas duas ou três vezes lá no PROCAP, mas a previsão era, tipo... Eu liguei... "Não. Só, provável, em janeiro do ano que vem!" Aí, eu já fiquei desanimado! Não tive e-mail e nem nada!"

E32: "Na verdade nesse curso eu não me inscrevi nele, só se eles acrescentaram o meu nome. Assim que eu entrei na instituição no início de 2010, eu fiz a sugestão que houvesse esse curso porque eu tive muita dificuldade quando eu entrei aqui e se eu não me engano esse curso só foi ofertado agora esse ano de 2012. Não fiquei sabendo que o meu nome constava da lista senão teria até participado."

Os entrevistados alegaram dificuldade de obterem informações que respondessem as suas dúvidas, bem como a comunicação existente não aconteceu de forma eficiente.

$\mathrm{Na}$ literatura estes aspectos foram tratados por Paredes (1994), que em seu estudo sobre a evasão em cursos presenciais de terceiro grau cita aspectos institucionais ou de caráter organizacional como um dos motivadores da evasão. Biazus (2003) também, ao estudar a evasão em universidades federais do sul do país relata que a orientação insuficiente, e a falta de informação motivam a evasão.

$\mathrm{Na}$ categoria 2, Incompatibilidade de horário exemplifica a dificuldade que os servidores encontraram em participar dos cursos no horário de trabalho.

\footnotetext{
E9: “... E muitas eram impossíveis de serem adiadas. Por exemplo: reunião do ..... Ninguém vai adiar porque eu tô na aula?! Então, eu tive que sair da aula várias vezes pra vir pra reunião, e acabei tendo que... é... sair do curso porque não tinha mais condições de eu ficar - eu já tinha um número de faltas... né?!... acima do permitido; aí, eu tive que abandonar! Não... Não consegui voltar ainda por causa disso: porque são em duas... em dois períodos inteiros... é... eu sei que eu vou acabar uma hora ou outra tendo que sair, porque tem alguma reunião." E27: "Eu me inscrevi porque além de servir para a progressão era interessante para as atividades que eu desenvolvia...não cheguei a cursar por causa da incompatibilidade de horário com as atividades que eu exercia aqui. Aqui nós trabalhamos em turnos até as vinte e três horas. O horário em que o curso era oferecido chocava com o meu horário de trabalho."
} 


\title{
CAUSAS DA EVASÃO EM CURSOS DE CAPACITAÇÃO DE TÉCNICOS EM INSTITUIÇÃO DE ENSINO SUPERIOR
}

DOI: http://dx.doi.org/10.5007/1983-4535.2013v6n1p287

$\mathrm{Na}$ categoria 3, pela Dificuldade de conciliar atividades diversas o inscrito não consegue conciliar o estudo com as sua atividades pessoais.

\begin{abstract}
E1: "Eu quis fazer o curso para ingressar no Mestrado... esses cursos pra gente deveria ser no horário de trabalho né, porque é o horário que a gente está na instituição né, porque se eles oferecem cursos fora do horário do nosso trabalho ai às vezes pra gente se adequar a esse horário fica ruim porque a gente às vezes tem outros compromissos nesses horários né, ai atrapalha a gente né, de repente se interessar e participar. Seria interessante que fosse no horário do expediente”. E8: "A data e o horário do curso inviabilizou a minha participação".
\end{abstract}

A categoria "dificuldade de conciliar atividades diversas" trata dos cursos realizados fora do horário de trabalho e que chocam com outras atividades pessoais do aluno. $\mathrm{Na}$ avaliação, do aluno, ele escolhe a atividade que considera de maior importância, a que tem mais interesse. Esse aspecto é abordado por Biazus (2003) que cita como motivador de ordem pessoal a opção por um dos seus interesses, quando o aluno tem que conciliar suas atividades

Já a categoria 4, Falta de interesse em fazer/concluir o curso, demonstra a ausência de comprometimento do inscrito. Veja exemplo da verbalização dos entrevistados.

E17: Então, você se inscreveu no curso de inglês instrumental que foi oferecido aqui pela instituição? "Várias vezes! Pelo menos, três! Eu já me inscrevi... mas eu tenho uma resistência começa a aborrecer e eu não quero! Aí, eu abandono! Normalmente, no meio! Não consigo chegar até o final! É igual à academia - eu começo a empolgar, aí, quando chega na metade, eu falo: "Eu não quero mais!" E33: "Eu me inscrevi só para saber como funcionaria um curso pelo PROCAP. Só 'pra' ter uma ideia, da facilidade de se inscrever, se teria dificuldade ou não, se teria vaga ou não, porque na verdade, especificamente nesse curso eu não tinha interesse."

A categoria "falta de interesse para fazer ou concluir o curso" se caracteriza quando falta ao inscrito interesse ou comprometimento em continuar com o curso. Biazus (2003) em seu estudo explica esta desmotivação como sendo causa de ordem pessoal ou mudança de interesse.

$\mathrm{Na}$ categoria 5, a Falta de apoio da chefia se define pela não autorização/liberação para realizar o curso. Segue exemplo da verbalização dos entrevistados.

\footnotetext{
E 27: "Eu me inscrevi porque além de servir para a progressão era interessante para as atividades que eu desenvolvia. Não cheguei a cursar por causa da incompatibilidade de horário com as atividades que eu exercia aqui. Não consegui liberação da chefia na época. E 28: "Os horários dos cursos são um pouco complicados e a gente tem que lidar com a nossa chefia imediata e nem sempre ela acha a melhor condição de sair e fazer um curso dentro do horário de trabalho, te liberar pra fazer um curso, por mais que este curso seja útil 'pro' ambiente de trabalho e se o seu trabalho demanda a sua presença, naquele momento o curso não é muito bem visto, então a gente acaba recuando."
} 


\title{
CAUSAS DA EVASÃO EM CURSOS DE CAPACITAÇÃO DE TÉCNICOS EM INSTITUIÇÃO DE ENSINO SUPERIOR \\ DOI: http://dx.doi.org/10.5007/1983-4535.2013v6n1p287
}

A "falta de apoio da chefia" foi a categoria que mais se manifestou na fala dos grupos de entrevistados. Caracteriza-se pela não liberação da chefia para a participação no curso em horário de trabalho. Muitas vezes a chefia libera o servidor para uma primeira aula, mas não para todos os dias, o que muitas vezes gera uma quantidade de faltas que inviabiliza a continuação no curso. Essa causa é considerada por Biazus (2003) como falta de apoio da organização onde trabalha, e que no caso deste estudo também é a ofertante do curso.

Na categoria 6, o "Excesso" de trabalho que caracteriza-se pela demanda no trabalho que impediu a participação no curso.

\begin{abstract}
E15: "Eu vi o curso e ele tinha relação coma as atividades que eu desenvolvo no meu trabalho. Eu não percebi que o curso era presencial e eu vi que não tinha como fazer o curso, porque o momento em que eu estava, né, a demanda de trabalho era muito grande e pra me ausentar neste periodo ia ficar bastante complicado, ai eu desisti. Nem cheguei a frequentar." E 25: "Falta de tempo. Não foi má vontade. Eu me inscrevi no curso e não recebi nenhuma confirmação, mas eu estava na época com muito trabalho, organizando um concurso então nem fui procurar para saber se eu estava inscrito ou não."
\end{abstract}

O "excesso de trabalho" foi relatado por alguns entrevistados como causa da evasão. Às vezes o servidor mesmo recebendo a liberação da chefia para o curso no horário de trabalho tem uma demanda específica para aquele período ou o acúmulo de tarefas que impede o servidor de se ausentar e então o mesmo evade do curso. A Comissão Especial de Estudos sobre a Evasão do Ministério da Educação (1997) entende que este fator evidencia a incompatibilidade da vida acadêmica com as exigências do mundo do trabalho.

$\mathrm{Na}$ categoria 7, o Horário das aulas, quando o curso era realizado no horário do almoço, na manifestação desses entrevistados, impedia sua participação.

\begin{abstract}
E24: "Eu me desliguei no começo, inclusive foi uma experiência que eu fui fazer, inclusive eu coloquei na avaliação que o horário é péssimo, não adianta, eu não consigo aprender nesse horário: eu não gosto de almoçar onze horas e não gosto de almoçar depois das quatorze. Foi uma experiência muito ruim, jamais vou fazer curso no horário do almoço. Já estou fazendo o curso de novo e em outro horário." E35: "Eu me inscrevi pro curso pois eu queria fazer a prova do Mestrado; eu desisti, eu nem comecei o curso. Na época eu mandei um email pra eles explicando que era por causa do horário. Eu tenho um problema de sáude e só posso me alimentar em horários específicos e o curso era no horário do almoço."
\end{abstract}

A categoria horário das aulas se refere aos cursos que são ministrados no horário do almoço. A verbalização dos entrevistados que compuseram esta categoria refere-se ao fato de que este horário não é o ideal e que deveria haver outras opções para o mesmo curso. Ao mesmo tempo outros entrevistados manifestaram-se favoravelmente a este horário por não ser 


\section{CAUSAS DA EVASÃO EM CURSOS DE CAPACITAÇÃO DE TÉCNICOS EM INSTITUIÇÃO DE ENSINO SUPERIOR \\ DOI: http://dx.doi.org/10.5007/1983-4535.2013v6n1p287}

o horário de trabalho e também não ser após o expediente. Para esta categoria específica devido a sua peculiaridade não foi encontrada referência na literatura que trata de cursos presenciais.

$\mathrm{Na}$ análise dessa categoria deve-se considerar que, com as mudanças nos horários da maioria dos servidores devido à flexibilização da jornada que se encontrava em processo de implantação na Instituição na ocasião da coleta de dados, havia a previsão de que a participação em ações de capacitação deveria ocorrer fora do horário de trabalho. Cabe ressaltar ainda que ao se inscrever em qualquer curso o servidor tinha acesso ao horário de sua realização.

A categoria 8, a Inadequação da composição da turma, indica que os critérios do curso não eram compatíveis com as necessidades dos alunos onde havia alunos na mesma turma com níveis diferentes de conhecimento. A seguir exemplo da verbalização dos entrevistados:

E9: "E aí, acaba que quem está muito avançado pode realmente ficar desmotivado perante alguém que está um pouco mais atrasado - principalmente no inglês instrumental, que é mais leitura e produção de texto! Então, a pessoa tem que ter um mínimo da língua, né?! Não tem como ela chegar e falar assim... O mínimo da gramática... Sem o minimo da formação de uma oração, né?!” E 22: “A professora mesmo que fez o teste de nivelamento já disse que não seria bom eu participar... eu já tinha inglês mais avançado do que o instrumental daqui. Nem cheguei a ir pra aula.".

$\mathrm{Na}$ categoria inadequação da composição da turma foi relatada pelos entrevistados que, mesmo para os cursos onde havia teste de nivelamento, como no caso de idiomas, eram admitidos alunos com diferenças significativas de conhecimento o que dificultava e desestimulava o aprendizado.

Na categoria 9, a Duração do curso, quando um dos módulos deixa de ser ofertado e a duração do curso se estende, na opinião do entrevistado, pode contribuir para uma taxa de evasão maior ou menor. A seguir temos um exemplo de verbalização.

E10: "Porque você começar o curso e demorar muito para terminar, a pessoa começa a ficar desestimulada. Você faz alguns módulos e tem que esperar para quando tiver professor para continuar o curso. Não sei! Eu, pelo menos, acho ruim né?! Pelo menos na minha opinião! Eu acho isso! Ai eu fui procurar um curso particular, paguei, já terminei e apresentei para a progressão.

Uma das categorias relatadas pelos evadidos diz respeito à duração do curso. O entrevistado disse que quando a duração de um curso se estende demasiadamente do que foi 


\section{CAUSAS DA EVASÃO EM CURSOS DE CAPACITAÇÃO DE TÉCNICOS EM INSTITUIÇÃO DE ENSINO SUPERIOR \\ DOI: http://dx.doi.org/10.5007/1983-4535.2013v6n1p287}

proposto no início, a tendência do aluno é a de perder a vontade de continuar por não ter ideia de quando poderá finalizar o mesmo.

$\mathrm{Na}$ análise da manifestação dos entrevistados, quanto às causas de evasão anteriormente citadas, percebe-se que não é dada a devida importância ao treinamento. A evasão injustificada denota em alguns casos a falta de comprometimento ou responsabilidade com a Instituição.

Quando há a oferta de um curso, são determinados e informados previamente a carga horária, a duração e o período de realização. A decisão de evadir com a alegação de que o curso é muito extenso não se justifica. Mas, quando se oferta um curso, quem se inscreve realiza um planejamento, principalmente quem intenciona aproveitar o treinamento para a progressão funcional.

A análise das categorias confrontada com a análise documental evidencia a falta de conhecimento dos inscritos quanto às características dos cursos, embora as informações fossem acessíveis no sítio da Instituição. As causas de evasão aferidas nesse estudo estão relacionadas ao inscrito, aos cursos e à instituição e a fatores socioculturais. No que se refere ao inscrito, destaca-se o comportamento do indivíduo ao decidir se o curso escolhido é importante o suficiente para que abdique de outras atividades que possam surgir no momento; o fator institucional que se relaciona com as regras de oferta pré-estabelecidas para que se possa avaliar o que está sendo oferecido e em que condições, e o comprometimento do servidor com a Instituição. Já os fatores socioeconômicos tratam também das relações com o trabalho que podem ser afetadas ou não pelo curso, mas não estão presentes nesse estudo.

\section{CONSIDERAÇÕES FINAIS}

O objetivo deste artigo foi o de identificar as causas da evasão que trará subsídios à definição de estratégias que possibilitem a redução das causas da evasão em cursos ofertados aos servidores de uma Instituição de Ensino Superior, na perspectiva de diferentes atores envolvidos no processo. Foi possível identificar nove categorias motivadoras da evasão apontadas pelos dos evadidos: dificuldade de acesso a informação junto à PROCAP, incompatibilidade de horário, dificuldade de conciliar atividades diversas, falta de interesse para fazer/concluir o curso, falta de apoio da chefia, excesso de trabalho, horário das aulas, inadequação da composição da turma e duração do curso. 


\section{CAUSAS DA EVASÃO EM CURSOS DE CAPACITAÇÃO DE TÉCNICOS EM INSTITUIÇÃO DE ENSINO SUPERIOR \\ DOI: http://dx.doi.org/10.5007/1983-4535.2013v6n1p287}

Também foram identificadas cinco categorias na percepção dos não evadidos: dificuldade de conciliar atividades diversas, falta de apoio da chefia, inadequação do curso às necessidades do aluno, realização de curso que não conta para a progressão, dificuldade de aplicação das regras de oferta dos cursos. Segundo os técnicos entrevistados, a evasão poderia ser motivada por incompatibilidade de horário, falta de apoio da chefia, duração do curso, dificuldade de aplicação das regras de oferta dos cursos Já os instrutores que ministraram os cursos apontaram como possíveis causas a necessidade de adequação do calendário dos cursos ao ano letivo e a falta de apoio da chefia.

O gestor entrevistado apontou como prováveis causas da evasão a dificuldade de aplicação das regras de oferta dos cursos, a falta de apoio da chefia, a falta de sistemas de apoio à capacitação e a necessidade de priorizar a capacitação no âmbito da Instituição.

As categorias mais citadas entre os grupos de entrevistados foram: dificuldade de acesso às informações junto à PROCAP; incompatibilidade de horário; falta de apoio da chefia e dificuldade de aplicação das regras de oferta dos cursos. Na literatura existe uma lacuna sobre o tema evasão pois são encontrados estudos sobre evasão em diversos níveis educacionais como ensino médio e superior, mas há uma escassez de estudos que abordem a evasão em cursos presenciais ofertados aos servidores públicos. A importância para a gestão pública do estudo das causas da evasão em cursos para servidores é a contribuição para a proposição de estratégias que visem sua redução no sentido de tornar as organizações mais ágeis e eficientes, reduzir os custos e melhorar a satisfação no atendimento às necessidades da sociedade.

A contribuição da literatura para este estudo foi a de corroborar as categorias oriundas dessa pesquisa. As manifestações de não evadidos, técnicos, instrutores e gestor têm pontos semelhantes à dos evadidos, mas apresentam uma nova perspectiva, ao abordar, por exemplo, as dificuldades de aplicação das regras de oferta dos cursos e a falta de sistemas de apoio à capacitação. Isso revela a importância da percepção de diferentes atores no contexto organizacional que a partir de sua experiência poderão contribuir para que se tenha uma visão mais ampla dos aspectos relacionados à evasão.

Foi observado que o maior índice de evasão ocorreu no início dos cursos. $\mathrm{O}$ inscrito não compareceu a nenhuma aula e cujas causas de evasão apresentadas foram: falta de libração da chefia, excesso de trabalho, horário das aulas e inadequação do curso às necessidades do aluno. Os resultados obtidos permitiram aferir algumas causas da evasão nos 


\section{CAUSAS DA EVASÃO EM CURSOS DE CAPACITAÇÃO DE TÉCNICOS EM INSTITUIÇÃO DE ENSINO SUPERIOR \\ DOI: http://dx.doi.org/10.5007/1983-4535.2013v6n1p287}

cursos de capacitação, possibilitando assim a proposição de possíveis estratégias que possam controlar esses fatores.

Sugere-se aprimorar os meios de comunicação. A criação de um espaço próprio na página principal da Instituição onde poderá obter todas as informações sobre a oferta de cursos. Sabe-se que a cartilha está disponível na página do Decanato de Gestão de Pessoas, mas por ser algo tão importante que atende a Comunidade, poderia ter seu espaço na página de abertura do sítio da Universidade. A disponibilização por email, que se agrega a todas as outras informações divulgadas pela Instituição torna muitas vezes difícil selecionar entre tudo o que se recebe aquilo que realmente é pertinente.

A dificuldade de aplicação das regras de oferta dos cursos: sugere-se o acompanhamento mais sistemático dos alunos inscritos. Recomenda-se maior contato com os instrutores e servidores participantes das ações de capacitação desde o início, para verificar a que se deve a ausência do aluno e atuar antes que a evasão ocorra.

A falta de interesse em fazer/concluir o curso: pela pesquisa realizada verificou-se o descaso com o abandono da parte do aluno. Deve-se levar em conta que nem todos os servidores tem acesso a computadores na instituição, assim cabe um levantamento desse público para que se busquem novas formas de comunicação que atinja a todos os servidores.

Conclui-se que em decorrência do reduzido número de estudos sobre evasão em cursos de capacitação presenciais destinados a servidores técnicos administrativos em instituições de Ensino superior, pode-se sugerir a serem abordados em futuros estudos a fim de proporcionar um maior entendimento sobre o assunto, tais como: comparação entre causas de evasão em cursos de capacitação presenciais e à distância; e comparação das taxas de evasão entre cursos de capacitação em outras IFES no país, além de que estudos de evasão integrem as atividades da área de gestão de pessoas das instituições como uma atividade de caráter permanente.

Buscou-se com o estudo apontar a importância de tal problema no contexto das instituições públicas de ensino superior como forma de estimular a busca da análise de suas causas e consequente planejamento de ações que visem sua redução. Com base nos resultados, foram apresentadas categorias comuns à evasão no ensino superior, mas também causas específicas, atinentes aos cursos de capacitação presenciais, que merecem atenção daqueles que gerenciam ações de capacitação nesse setor. 


\section{REFERÊNCIAS}

ABBAD, G. Um modelo integrado de avaliação do impacto do treinamento no trabalho IMPACT. Brasília, 1999, 347 p. Tese (Doutorado em Psicologia). Instituto de Psicologia, Universidade de Brasília.

BARDIN, L. Análise de Conteúdo. São Paulo: Edições 70, 2011. P.33-52 e 123-132.

BEAN, J. P. The application of a model of turnover in work organizations to the student attrition process. Review of Higher Education, New York, n. 6, p. 129-148, 1983.

Dropouts and turnover: the synthesis and test of a causal model of student attrition. Research in Higher Education, Baltimore, v. 12, n. 2, p. 155-187, 1980.

BIAZUS, C. A. Sistema de fatores que influenciam o aluno a evadir-se dos cursos de graduação na UFSM e na UFSC: um estudo no Curso de Ciências Contábeis.

Florianópolis, 2003, 203 p. Tese de Doutorado. Disponível em:

$<$ http://teses.eps.ufsc.br/defesa/pdf/11295.pdf >. Acesso em: 16 nov. 2011.

BORDAS, M. C. Diplomação, retenção e evasão nas universidades públicas brasileiras. In: FORUM NACIONAL DE PRÓ REITORES DE GRADUAÇÃO, 1996, Florianópolis. Disponível em: <http://www.ufrgs.br/faced/edp50/acervo.html>. Acesso em: 16 nov. 2011

BORGES-ANDRADE, J.E. Desenvolvimento de medidas em avaliação de treinamento. Estudos de Psicologia (UFRN), Natal, RN, v. 7, n. Especial, 2002, p. 31-43.

BORGES-ANDRADE et al. Treinamento, desenvolvimento e educação em organizações e trabalho para a gestão de pessoas. Porto Alegre: Artmed, 2006.

BRASIL, Decreto no 5.707 de 23 de fevereiro de 2006. Institui a Política e as Diretrizes para o Desenvolvimento de Pessoal da administração pública federal direta, autárquica e fundacional, e regulamenta dispositivos da Lei $\mathrm{n}^{\circ} 8.112$, de 11 de dezembro de 1990. Diário Oficial [da] República Federativa do Brasil, Poder Executivo, Brasília, DF, 24 fev. 2006. Acesso em 08 de novembro de 2012.

BRASIL, Decreto $n^{0} 5.825$ de 29 de junho de 2006. Estabelece as diretrizes para elaboração do Plano de Desenvolvimento dos Integrantes do Plano de Carreira dos Cargos TécnicoAdministrativos em Educação, instituído pela Lei no 11.091, de 12 de janeiro de 2005. Diário Oficial [da] República Federativa do Brasil, Poder Executivo, Brasília, DF, 29 jun. 2006. Acesso em 08 de novembro de 2012.

BRASIL. Ministério da Educação e Cultura. Secretaria de Educação Superior. Comissão Especial de Estudos sobre a Evasão nas Universidades Públicas Brasileiras. Brasília, 1996/1997. Disponível em http://www.dominiopublico.gov/download/texto/me001613.pdf. Acesso em: 03 nov. 2011. 
CARDOSO, C.B. Efeitos da política de cotas na universidade de Brasília: uma análise do rendimento e da evasão. 2008. 132p. Dissertação (Mestrado) - Faculdade de Educação. Universidade de Brasília, Brasília.

CASTAÑO, E. et al. Análisis de los factores asociados a la deserción y graduación estudiantil universitaria. Lecturas de Economia, n. 65, p.11-35, 2006.

COSTA, W. S. J. Evasão em cursos gratuitos: uma análise de suas principais causas e identificação de perfil dos alunos evadidos no SENAC Sete Lagoas. 2010. Dissertação. Faculdades São Leopoldo.

FLICK, U. Introdução à Pesquisa Qualitativa. 3. ed. Porto Alegre: Artmed, 2009. Cap. 3 e 11.

GAETANI, F. Capacitação de recursos humanos no serviço público: problemas e impasses. Revista do Serviço Público, Brasília: ENAP. Texto para discussão n.27, jun. 1998.

GAIOSO, N. P. de L. O fenômeno da evasão escolar na educação superior no Brasil. Relatório. Brasília, Pró-Reitoria de Pós-graduação e Pesquisa, Universidade Católica de Brasília, 2005. 75p. Biblioteca da Pontifícia Universidade Católica de Brasília. Dez. 2011.

GUION, L. A. Triangulation: Establishing the Validity of Qualitative Studies. IFAS, University of Florida, Set. 2002.

HAMBLIN, A. C. Avaliação e controle do treinamento. São Paulo: McGraw-Hill do Brasil, 1978. Biblioteca da UNICEUB. Julho de 2011.

LÜDKE M. et al. Pesquisa em Educação - Abordagens Qualitativas. 1. ed. São Paulo: Editora EPU, 1986. p. 25-44.

MENEGASSO, M. E., SALM, J. F. A educação continuada e a capacitação gerencial: discussão de uma experiência. Revista de Ciências da administração, Florianópolis, UFSC, ano 3, n. 5, mar./2001, p. 27-35.

PAREDES, A. S. A evasão do terceiro grau em Curitiba. São Paulo: Núcleo de Pesquisa sobre Ensino Superior da Universidade de São Paulo, 1994. Documento de Trabalho NUPES, $6 / 94$.

PASCARELLA, E. College environmental influences on learning and cognitive development: A critical review and synthesis. In J. Smart (Ed.), Higher education: Handbook of theory and research (Vol. 1). New York: Agathon, 1985.

PASQUALI, L. Princípios de elaboração de escalas psicológica Revista Psiquiatria Clínica v.25 n. 5 Edição Especial, p. 206-213, 1998.

PEIXOTO, M. C. L.; BRAGA, M. M. A evasão no ciclo básico da UFMG. Educação On Line. Publicado em: 2 dez. 2001. Disponível em: <http://www.

educacaoonline.pro.br/a_evasao_ufmg.asp?f_id_artigo=279>. Acesso em: 20 dez. 2011. 
SPADY, W. Dropouts from higher education: an interdisciplinary review and synthesis. Interchange, 1970, I, p. 64-85.

SILVA FILHO, R. L. L. et al. A evasão no ensino superior brasileiro. Cadernos de Pesquisa, v.37, n.132, p. 641-659, 2007.

TINTO, V. "Dropout from Higher Education: A Theoretical Synthesis of Recent

Research" p.41-43. Report - Office of Planning, Budgeting and Evaluation of the U. S. Office of Education, 1973. http://www.eric.ed.gov/ERICWebPortal/search/recordDetails.jsp? Acesso em: 20/12/2011.

VELOSO, T. C. M. A. Evasão nos cursos de graduação da Universidade Federal de Mato Grosso, campus universitário de Cuiabá: um processo de exclusão. $24^{\mathrm{a}}$ Reunião Anual da ANPED, 2001, Caxambu. Evasão nos cursos de graduação da Universidade Federal de Mato Grosso, campus universitário de Cuiabá: um processo de exclusão. Rio de Janeiro: Vozes, 2001. Disponível em: $<$ http://www.anped11.uerj.br/24/Veloso.doc $>$. Acesso em: $02 \mathrm{dez}$. 2011.

ZANELLI, J.C. Pesquisa qualitativa em estudos da gestão de pessoas. Pesquisa Social em Psicologia. v. 7, p. 79-88, 2002.

ZERBINI, T. Avaliação de transferência de treinamento em curso à distância. Brasília, 2007. Tese (Doutorado em Psicologia). Instituto de Psicologia, Universidade de Brasília. 